\title{
Health Data in Fertility Care: An Ecological Perspective
}

\author{
Mayara Costa Figueiredo \\ University of California, Irvine
}

\begin{abstract}
Fertility tracking and technology are characterized by logging varied health-related data potentially associated with female fertility cycles. Such data are often seen as private and restricted to the individual level. We conducted an interview study with 21 people (16 in the U.S.) facing challenges to conceive and 5 U.S. healthcare providers specialized in infertility to analyze (in)fertility experiences with data. Our findings suggest that although fertility data are considered personal and private, they are embedded in larger ecological systems of use, influencing and being influenced by different stakeholders, institutional contexts, and sociocultural factors. Leveraging the Ecological Systems Theory, we analyze the relationships and factors shaping individuals' fertility trajectories, discussing how the different layers influence the work individuals have to engage and the burden imposed on them through various social, institutional, and cultural boundaries. We propose an ecological perspective on fertility data practices and discuss opportunities to counter-influence broader environmental systems through data tracking.
\end{abstract}

\section{CCS CONCEPTS}

- Human-centered computing $\rightarrow$ Human computer interaction (HCI); Empirical studies in HCI; Collaborative and social computing; Empirical studies in collaborative and social computing; • Applied computing $\rightarrow$ Life and medical sciences; Health informatics.

\section{KEYWORDS}

Personal Informatics, Fertility self-tracking, Ecological models

\section{ACM Reference Format:}

Mayara Costa Figueiredo and Yunan Chen. 2021. Health Data in Fertility Care: An Ecological Perspective. In CHI Conference on Human Factors in Computing Systems (CHI '21), May 08-13, 2021, Yokohama, Japan. ACM, New York, NY, USA, 17 pages. https://doi.org/10.1145/3411764.3445189

\section{INTRODUCTION}

With the uptake of self-tracking technologies [65], individuals are using personal data for varied health issues, from general wellbeing [85] to managing health conditions such as diabetes [58] and cancer [53]. The engagement with personal health data has typically been seen as individual-driven or self-oriented. However, recent studies show that self-care is highly collaborative [77] and self-tracked data influence and are influenced by individuals' relationships and

Permission to make digital or hard copies of all or part of this work for personal or classroom use is granted without fee provided that copies are not made or distributed for profit or commercial advantage and that copies bear this notice and the full citation on the first page. Copyrights for components of this work owned by others than the author(s) must be honored. Abstracting with credit is permitted. To copy otherwise, or republish, to post on servers or to redistribute to lists, requires prior specific permission and/or a fee. Request permissions from permissions@acm.org.

CHI '21, May 08-13, 2021, Yokohama, Japan

(C) 2021 Copyright held by the owner/author(s). Publication rights licensed to ACM. ACM ISBN 978-1-4503-8096-6/21/05...\$15.00

https://doi.org/10.1145/3411764.3445189

\author{
Yunan Chen \\ University of California, Irvine
}

the contexts where the self-tracking activities are situated [75]. A growing body of research has focused on the collective aspects of health data, investigating topics such as using data to support patient-providers collaboration [90, 91], caregivers' experiences of tracking those being cared [66], and collaborative data tracking in families [81, 88]. These studies cover a wide range of stakeholders who directly interact with individuals and can be directly impacted by their self-tracking practices. Beyond direct relationships and interactions, other social environments and contexts may also influence the ways individuals use personal data. For example, perceived neighborhood characteristics (e.g., presence of parks or incidence of crime) may impact individuals' ability to perform physical activity, thus, influencing their self-tracked exercise data [87]. Other studies have discussed how self-tracked data are shaped by the broader social, cultural, and political institutions and ideologies in which individuals are embedded $[68,93]$. These studies call attention to the different forms of social and environmental contexts involved in individuals' self-tracking activities and data.

Inspired by this body of research, this study approaches the ecologies of care involved in the experiences of individuals facing fertility challenges, a highly personal health context entangled with varied institutional needs and societal taboos. Although infertility is not uncommon (13.1\% of U.S. women of age 15-49 in 2017 [19] and 48.5 million couples worldwide in 2012 [71]), it is still largely invisible: individuals often are not aware of how common it is, the burden of struggling with infertility is underestimated [102], and the various loss associate with it (i.e., not only a pregnancy but an entire envisioned life stage-parenthood) are not recognized [72]. Fertility is also data intensive [23] and has been increasingly supported by self-tracking technologies, especially mobile apps, that promise to support individuals' conception efforts by helping them to time intercourse around ovulation. Such practices are expected to directly impact the outcomes of their fertility trajectories.

Fertility tracking technologies are characterized by logging varied health-related data potentially associated with female fertility cycles. Such data are often seen as private and individual. However, although (in)fertility is considered a private matter, it is not isolated from the influences and interactions with other stakeholders. Partners and healthcare providers are often directly involved in individuals' fertility trajectories (i.e., their journeys towards conception). Others, such as family and friends, are also important relationships that can positively (e.g., supporting) or negatively (e.g., pressuring) affect individuals' fertility experiences. However, it is still unclear how all these relationships are influenced by the intense data practices individuals engage in when trying to conceive. Furthermore, fertility care is clearly influenced by organizations such as healthcare institutions and societal taboos related to the female body.

We conducted an interview study with people facing fertility challenges and healthcare providers specialized in infertility to understand people's (in)fertility experiences and their engagement 
with personal health data. Leveraging the Ecological Systems Theory (EST), we explore the larger ecological systems of use in which fertility data are embedded, and how these data influence and are influenced by different stakeholders, institutional spaces, and sociocultural factors present in the context of our participants (i.e., mostly U.S. and western environments). We discuss how these different interactions influence the data work individuals have to perform and the burden imposed on them through various social, institutional, and social boundaries. We then discuss opportunities to counter-influence broader societal contexts through personal health data. This study provides the following contributions: (i) we provide a rich description of fertility ecologies of care, describing how fertility data influence and are influenced by different stakeholders, institutional spaces, and sociocultural factors, (ii) we discuss how the entanglement between data work and the multiple layers of influence adds burden on individuals, and (iii) we discuss opportunities for using data to counter-influence from inside out. Finally, our findings point to the importance of taking a wide lens when analyzing the influence of self-tracking technologies, focusing on more than activities of data collection and use. Such approach is important to HCI because these activities and the technologies that support them do not exist in isolation and often involve managing personal data amidst individuals' daily lives and interacting and coordinating with different stakeholders, technologies, and institutions.

\section{BACKGROUND: (IN) FERTILITY TRAJECTORIES}

Fertility is complex [92], sensitive, and entangled with taboos [1] and life goals [11]. Couples often start their fertility trajectory trying to conceive without medical assistance for 6 to 12 months [92]. At this stage, trying to conceive can be data intensive [22, 23] individuals may track a wide variety of health-related data, such as menstrual cycle days, basal body temperature (BBT), ovulation predictor kits' (OPKs) results, cervical mucus, and symptoms, to identify ovulation and time intercourse with the fertile window (i.e., period of the cycle when pregnancy is possible [92]). However, these data can be very complex to analyze since none of them can precisely pinpoint ovulation. For example, OPKs measure a rise in the Luteinizing Hormone (LH) before ovulation while the BBT, the lowest body temperature, rises by 0.5-1 degree Fahrenheit the day after ovulation [23]. As a result, many individuals engage in intense self-tracking, increasingly supported by technology (e.g., mobile apps), to compare and make sense of different types of health-related data.

If couples do not conceive during this time, they may seek help from medical professionals, from family doctors, to gynecologists, and eventually Reproductive Endocrinology and Infertility specialists (REIs), with varying costs that may not be covered by health insurances. Besides treating any underlying physical (e.g., tubal occlusion) or hormonal (e.g., PCOS) issues, some of the main fertility treatments are to medically stimulate ovulation, intrauterine insemination (IUI), and in vitro fertilization (IVF) [82]. Even with medical treatment, individuals' data are still central to fertility: diagnosis and treatments require patients and providers to track patients' cycles to define and time treatment appropriately.

\section{RELATED WORK}

\subsection{Fertility-Related Research in HCI}

A growing body of HCI research has focused on how technology can support different needs associated to female bodies and experiences. Although pregnancy has been historically studied, with research on issues such as excessive gestational weight [80] and information seeking behavior [44], stages pre- and post-pregnancy have been less examined. Many people face challenges to conceive and recent studies have explored how individuals use self-tracking to try to overcome them $[23,49,50]$ and online forums for support $[22,79]$, especially when living painful related events, such as pregnancy loss $[4,5]$. Studies centering the parent post-pregnancy have analyzed issues such as finding places to breastfeed [8], pumping experiences [28], and the struggles of dealing with fragmented healthcare systems $[45,46]$, highlighting the lack of support individuals face.

Because of the gaps in knowledge related to the natural complexity of fertility [92] and the taboos related to the female body [1], several studies have focused on technology to support menstrual education $[54,98,99]$ and how people use online spaces to find information, support, and make sense of their experiences in varied fertility-related contexts, such as menopause [63], infertility [22, 23], endometriosis [73], and vulvodynia [103]. With the increasing availability of menstrual tracking apps, other studies have analyzed users' goals and challenges [33, 42], the information provided by these apps [34], privacy concerns [37], and normative stereotypes of female bodies reinforced by such technologies [33, 41]. Another line of work has focused on challenging such taboos by using alternative and speculative design [2, 10, 17, 18, 48], removal of self-tracking technologies [50], and feminist approaches to question the design of public infrastructures and related technologies $[40,41]$.

These studies suggest that fertility-related issues involve aspects beyond the bodies of people who menstruate, including challenges entangled with broader aspects of their lives, such as education, stigma, social taboos, infrastructure breakdowns, and lack of support. Our study approaches self-tracking for the goal of conceiving, a fertility-related issue that involves all these challenges and, in addition, is very data intensive [23]. Besides, fertility trajectories are hardly individual (they often involve a partner and healthcare providers who are also influenced by individuals' data practices) and fertility self-tracking technologies are becoming increasingly entangled with our activities, bodies, and lives $[22,50]$.

\subsection{Self-Tracked Data Beyond The Self: Ecologies Of Care}

Although the name suggests an individual activity, self-tracking and is often not exclusively personal, especially in the health domain. Various aspects of health affect and are affected by multiple relationships $[9,81]$ and several studies have explored how individuals' self-tracking activities influence or are influenced by such relationships. For instance, patient-provider relationships have been largely explored in $\mathrm{HCI}[30,96]$, with many studies focusing on how self-tracked data influence clinical encounters and shared-decision making $[20,91]$. Such studies report how data can ally providers' 
medical expertise with patients' knowledge about their illness experiences [91], but both patients and providers face challenges in supporting each other's data needs [83, 90].

Other relationships that have been studied include partners, family, and caregivers [51, 81]. Studies analyzing the influence of self-tracking in the family have discussed aspects of motivation [57], privacy [51, 81], division of labor [3], and burden of caregiving, particularly when caregivers track the individual [59]. For example, Mishra et al. [74] describe individuals with Parkinson's disease appreciate their partners' support in tracking symptoms they cannot perceive (e.g., sleep) but tensions arise with conflicting interpretations of ambiguous symptoms. In the fertility context, Homewood et al. [49] developed a self-tracking device to support shared use by couples, however despite their intentions, tracking was still mostly centered in the partner who would carry the baby. Other studies describe how individuals use data to make an invisible condition visible to others from both close (e.g., family) and extended networks (e.g., work colleagues) [36, 70].

Most of these studies focus on one type of relationship (e.g. family). However, a growing body of research has considered the role of technology within ecologies of care, approaching multiple relationships at once. For example, Evans et al. [35] examined the care ecologies of veterans with PTSD, analyzing how relationships with clinicians, trusted others, and non-human intermediaries (e.g., technology systems) support the veteran. Other studies have included not only relationships, but infrastructure and social aspects as important forces shaping individuals' self-tracking activities. Parker et al. [78] argue that health cannot be reduced to an individual effort of changing behaviors and health interventions need to engage with broader community and socio-cultural forces that shape individuals' living conditions. Peyton et al. [80] investigated social, demographic, cultural, and economic factors that influence the gestational weight of pregnant lower-income American women. Finally, Murnane et al. [75] explored self-tracking as a collective endeavor that is embedded in multiple social structures. They used the EST $[14,15]$ to propose an ecological model that includes an informatics layer to account for the mediation role data play in the social ecology of serious mental illness.

Our work builds directly on this previous research that highlight the importance of taking an ecological perspective that considers the multiple stakeholders involved in health and illness contexts $[62,75]$. Our study is particularly inspired by Murnane et al. [75] use of the EST, since self-tracked data play an important role in (in)fertility experiences [22, 23], influencing and being influenced by different stakeholders, institutional contexts, and sociocultural factors. Thus, we leverage the EST to investigate how these multiple influences manifest during the fertility trajectories of individuals' facing challenges to conceive. Our results suggest that the influence of data is more structured and intense in the fertility context, in which individuals are expected to take responsibility to directly influence the outcomes of their fertility trajectories through personal actions based on their data [64, 69]. Self-tracking is then seen as a possible way to directly control individuals' fertility trajectories [22], a belief that is largely influenced by societal views of healthcare (e.g., one needs to take responsibility for their health) and expectations about gender (e.g., women are responsible for conceiving).

\section{THEORETICAL FRAMEWORK: THE ECOLOGICAL SYSTEMS THEORY}

First introduced for early children development, the EST describes how individuals are influenced by different types of environmental systems that interact with and influence each other [15]. The EST model is composed of five nested layers or systems that form the ecology of human development: the microsystem encompasses the immediate settings and relationships that surround the individual, usually including family, friends, and peers. The mesosystem represents the interrelations between the microsystem entities (therefore sometimes it is omitted from graphical representations [75]). The exosystem comprises other settings and or organizations that surround the individual, such as workplace, government agencies, and healthcare systems. Last, the macrosystem encompasses broader socio-cultural patterns, such as educational, political, social, and economical systems that are manifested in the other systems $[14,15]$. Besides these main layers, the model also includes a chronosystem [15], which encompasses the dimension of time and accounts for changes in environments during life transitions and throughout the individual's life course. Since its creation, the EST has been widely used as a theoretical framework in a variety of areas to explain and explore human relationships with the surrounding environments, including studies that explore computational support for autism [6], substance use disorders [104], serious mental illness [75], and asthma [55]. Similarly, this study uses the EST to investigate how individuals' fertility data tracking is influenced by these multi-layer environmental systems and to explore ways to better support individuals' fertility trajectories through an ecological perspective.

\section{METHODS}

To investigate individuals' (in)fertility experiences and their ecologies of care, we conducted an interview study with people who have faced or are facing challenges to conceive for at least 6 months and with medical specialists who directly work with infertility. We approach the ecological model from the perspectives of the individual with female fertility who is trying to conceive (the "individual" in the center of our model) to show how their fertility experiences are situated in their complex relationships with others. The interviews with partners and healthcare providers were used to understand their interactions with individuals. We did not interview stakeholders from outer layers of the model but addressed these relationships through individuals' accounts of their interactions with different roles, organizations, institutions and broader social systems.

\subsection{Recruitment}

We recruited participants in three ways: (i) we used snowball sampling, (ii) we partnered with a fertility clinic located in the west coast of the U.S. to distribute the research flyer, and (iii) we posted the flyer in an online health community $(\mathrm{OHC})$ focused on trying to conceive (TTC). These recruitment methods allowed us to obtain participants with rich and varied experiences, from the ones managing infertility on their own to those who have gone to extensive clinical treatments. In total, we recruited 19 individuals, 2 partners (hereafter represented by P1 to P21), and 5 REIs (D1 to D5). 
Table 1: Individuals' and partners' characteristics

\begin{tabular}{|c|c|c|c|c|c|c|c|c|c|}
\hline $\mathrm{P \#}$ & Age & $\begin{array}{l}\text { Age } \\
\text { TTC }\end{array}$ & $\begin{array}{l}\text { Time } \\
\text { TTC }\end{array}$ & Conceived & Gender & Ethnicity & $\begin{array}{l}\text { Highest } \\
\text { degree }\end{array}$ & Marital status & Profession \\
\hline $\mathrm{P} 1$ & 43 & $25 / 37$ & $\begin{array}{l}4 y 6 \mathrm{~m} / \\
1 \mathrm{y}\end{array}$ & Yes / Yes & Female & Philippine/Italian & BA & $\begin{array}{l}\text { Divorced, } \\
\text { Married }\end{array}$ & Transcriptionist \\
\hline $\mathrm{P} 2$ & 43 & 36 & $7 y$ & Yes & Female & White & BA & Married & Beauty industry \\
\hline P3 & 35 & $29 / 33$ & $1 \mathrm{y} / 6 \mathrm{~m}$ & Yes / Yes & Female & White & MS & Married & Pre-school teacher \\
\hline $\mathrm{P} 4$ & 35 & $29 / 32$ & $2 y / 3 y+$ & Yes / No & $\begin{array}{l}\text { Female } \\
\mathrm{b}\end{array}$ & Hispanic & College & Married & Stay at home mom \\
\hline P5 & 30 & $24 / 27$ & $2 y / 3 y+$ & Yes / No & Male $^{b}$ & Caucasian & $\begin{array}{l}\mathrm{PhD} \text { in } \\
\text { progress }\end{array}$ & Married & $\mathrm{PhD}$ student \\
\hline P6 & 32 & 28 & $4 y+$ & No & Female & White & Bachelors & Married & Teacher \\
\hline P7 & 40 & $39^{\mathrm{a}}$ & $1 y^{+}$ & No & Female & $\begin{array}{l}\text { White/Ashkenazi } \\
\text { Jew }\end{array}$ & MS & Married & Speech therapist \\
\hline P8 & 34 & 30 & $4 y+$ & No & Female & $\begin{array}{l}\text { Asian } \\
\text { Korean/Hmong }\end{array}$ & - & Married & $\begin{array}{l}\text { Math and Science } \\
\text { instructor }\end{array}$ \\
\hline P9 & 40 & 30 & $10 \mathrm{y}$ & Yes & Female & Asian Chinese & MS & Married & Accountant \\
\hline $\mathrm{P} 10$ & 34 & $32 / 34$ & $\begin{array}{l}1 \mathrm{y} / \\
5 \mathrm{~m}+\end{array}$ & Yes / No & Female & Hispanic & Bachelors & Married & $\begin{array}{l}\text { Medical field } \\
\text { representative }\end{array}$ \\
\hline P11 & 39 & 24 & $2 y$ & Yes & Female & White European & $\mathrm{PhD}$ & $\begin{array}{l}\text { Divorced, } \\
\text { Married }\end{array}$ & Professor \\
\hline $\mathrm{P} 12$ & 31 & 29 & $1 \mathrm{y} 6 \mathrm{~m}$ & No & Female & Brazilian white & $\mathrm{PhD}$ & Married & Professor \\
\hline $\mathrm{P} 13$ & 28 & 23 & $2 y 8 m$ & Yes & Female & Caucasian white & BS & Married & Software engineer \\
\hline P14 & 49 & $28 / 37$ & $6 y / 1 \mathrm{~m}$ & Yes / Yes & Female & Caucasian & BA & Married & Non-profit worker \\
\hline $\mathrm{P} 15$ & 31 & 29 & $3 y+$ & No & Female & $\begin{array}{l}\text { Caucasian } \\
\text { Hispanic }\end{array}$ & $\mathrm{PhD}$ & Married & Post-doc fellow \\
\hline P16 & 33 & 30 & $4+$ & No & Female & Brazilian & $\begin{array}{l}\text { MS in } \\
\text { progress }\end{array}$ & Married & Physician \\
\hline P17 & 30 & 28 & $2 \mathrm{y} 2 \mathrm{~m}+$ & No & Female & Caucasian & $\mathrm{JD}$ & Married & Attorney \\
\hline P18 & 31 & 28 & $3 y 6 m+$ & No & Female & Caucasian & Some college & Married & Concierge \\
\hline P19 & 34 & 30 & $2 y$ & Yes & $\begin{array}{l}\text { Female } \\
\mathrm{c}\end{array}$ & Latina white & College & Married & Program manager \\
\hline P20 & 41 & 37 & $2 y$ & Yes & Male $^{\mathrm{c}}$ & Brazilian white & $\mathrm{PhD}$ & Married & Professor \\
\hline $\mathrm{P} 21$ & 41 & 38 & $2 y+$ & No & Female & White & MS & Married & Researcher \\
\hline
\end{tabular}

"y" stands for years; "m" for months, and "+" indicates the person is still trying to conceive. ${ }^{a}$ : P7 conceived the first child with no challenges but is facing challenges to conceive the second. ${ }^{b, c}$ : Partners

Most of our individual participants were recruited through snowball sampling (10) or from the OHC (6), having no connections to the fertility clinic. Although many patients from the clinic were interested in our research, only three contacted us and completed the study. Partners were recruited from snowball sampling: we asked each individual if they were willing to refer their partners, if there was one, but only two partners agreed in participating (P5 and P20, partners of $\mathrm{P} 4$ and $\mathrm{P} 19$ respectively). 16 of our individual participants were located in the U.S. The others were located in Brazil (3), Portugal (1), and the U.K (1). Table 1 summarizes the characteristics of individuals and partners using the terms they used in their answer. Since some participants faced challenges conceiving more than one child, we use "/" to separate information for their first child / second child.

All five REIs were recruited from the same U.S. fertility clinic we partnered with. We will not disclose the name and location of the clinic nor the name of the $\mathrm{OHC}$ to protect participants' anonymity.
To further protect providers' identity, we use a neutral pronoun to refer to them to avoid possible identification based on their gender. All participants verbally consented to participate and received compensation for their participation. Our study was approved by the Institute Review Board prior to recruitment and data collection.

\subsection{Data Collection}

Interviews with individuals and partners followed a narrative approach $[32,56]$ to solicit their lived experiences and situated life events during their fertility trajectory. Narrative interviews support the investigation of ecologies of care because they foreground the context of people's experiences and their own explanations about them [32, 56]. The interviews happened as follows [56]: first, the first author explained the project (initiation phase) and used "a generative narrative question" [84] (i.e., can you tell me about your experience trying to conceive?) to invite participants to share their personal experiences (main narration), signaling attentive listening 
to encourage the participant and taking notes when necessary. After the participant clearly signaled ending the narrative, the first author asked clarifying questions (questioning phase), to guarantee a clear understanding of their fertility trajectories, and follow-up questions when certain aspects were not described sufficiently.

We used semi-structured interviews with healthcare providers because such method allows for openness of responses and for ensuring all aspects of interest were covered. Because our focus was on individuals' experiences and the influences on them, our goal with providers' interviews was on their interactions with patients, not on their own work experiences or the factors that affect their work experiences. Therefore, semi-structured interviews were more appropriate for this case. We developed the interview protocol based on previous literature review and an initial meeting with the clinic. The interviews focused on (i) healthcare providers' experiences conducting fertility treatments, (ii) their attitudes towards selftracking technologies and data, and (iii) their views of patients' infertility experiences.

Interviews lasted from 23 minutes to 1 hour 21 minutes. Two interviews were conducted in person, while the other 24 were online or via phone calls. Each interview generated rich descriptions of participants lived experiences, work and self-tracking practices, and the main relationships of their ecologies of care.

\subsection{Data Analysis}

All interviews were recorded and transcribed. We used a mix of inductive and deductive approaches to data analysis [26] in two different stages. First, the authors read a subset of interviews to discuss themes and identify ways of coding the data. The first author then coded the whole dataset in an inductive manner. Relationships (individual-partner, individual-providers, individual-others), data interactions (individual-data, partner-data, provider-data, othersdata), infrastructure, learning, and emotional experiences are some examples of codes that emerged from this analysis. At this point, we identified the influence of multiple stakeholders and the different levels of environmental systems involved in participants fertility trajectories specific to our data. The authors then decided to leverage the EST $[14,15]$ as a theoretical framework to reanalyze the interviews and explore the ecologies of care involved in fertility trajectories and better explore the different relationships described by our participants, the role data plays, and how data influences their experiences. In this second stage of analysis, the first author re-analyzed the whole dataset conducting open and focused coding [89] focusing on the layers of the ecological model, individuals' main relationships with others and institutions, the relations among them, and how this whole ecology influences individuals' fertility trajectories. The authors met regularly throughout the whole coding process to discuss data analysis.

\subsection{Limitations}

This study has limitations that reflect the challenging nature of this population and the nature of the model. First, because fertility is sensitive, invisible, and stigmatized, recruitment is generally difficult. This is reflected in the low diversity of our sample: participants were all heterosexual cis people, not representing diverse experiences and critical challenges faced by other couples and individuals who menstruate. Our sample also does not include Indigenous, Black, and other minoritized individuals who may experience diverse influences particularly in the exo and macrolevel. Second, most of our participants (16) live in the U.S., therefore, as many of the factors in the ecological model are culturally and institutionally shaped, our findings can only speak to the U.S. or western situations. Third, although the EST model includes various stakeholders and different institutional and social factors, it is challenging and near impossible for us to study all the involved entities as many of them are unknown and invisible to us (e.g., the designer of fertility app, the insurance representative). Thus, we opted to focus on individuals and to unpack the relationships through their lived experiences. We attempted to recruit their partners and the selected health professionals with fertility treatment expertise. However, due to the sensitivity of fertility, we were not able to even recruit enough male partners.

\section{RESULTS}

In this section, we first provide an overview of fertility data practices. We then describe the application of the EST to the fertility context, reporting data use in each layer, including how data mediate relationships and support treatments, how different personal and institutional spaces need to be coordinated with data, and how broader socio-cultural patterns influence individuals' fertility experiences and data.

\subsection{Fertility Data Practices: Tracking The Female Body}

Pregnancy is often seen as "a natural thing that happens" [P10] and is central to many people's life plan. The combination of complexity, invisibility, and life goals creates stress and stigma for individuals facing challenges to conceive (e.g., "you feel alone, and you feel defective" [P14]). Hence, individuals turn to data tracking in the hope of increasing their chances of pregnancy and sense of control. Fertility self-tracking focuses on two main activities: (i) to identify the fertile window to time intercourse or fertility treatments around ovulation, and (ii) to identify early signs of pregnancy [23]. With these goals in mind, individuals track various types of personal data. The most common ones are period days (tracked by all 19 female participants) and intercourse (tracked by 12), but individuals also track other health indicators that can be used to identify ovulation: 16 participants used OPKs, 13 used temperature, 8 used cervical mucus, 1 used cervical position, 3 used pulse, 1 used saliva, and 10 used general symptoms. Most of these data are also tracked to identify early signs of pregnancy. Participants also mentioned tracking period flow (2), menstrual pain (2), medication (4), and vitamins (5). Finally, individuals also monitor multiple lifestyle factors, such as weight (4), sleep (4), mood (4), stress (2), diet (11), and exercise (9) "to improve my health" [P8] or to identify the reason why they are not conceiving. They tracked different combinations of these data in different moments of their trajectories. They performed these activities using paper (2), computer software (3, e.g., Excel), fertility apps (14, e.g., Clue, Glow, Fertility Friend, Ovia), wearables (5, e.g., Ava, OvuSense), mini microscopes (1), or a combination of these. Lifestyle measures in particular were commonly tracked only 
by memory. These activities are performed within each menstrual cycle, with some data tracked once a month.

Tracked data can help individuals learn about their bodies (e.g., "helping us to be more aware of our bodies and how they function is pretty cool" [P11]) and support diagnosis and treatment (e.g., "the doctors would be like 'Make sure you track your ovulation and if you ovulate before, you need to call us" [P10]). It can also help individuals to set appropriate fertility expectations: "it [app]. . .tells you. . .how much of an outlier that cycle is...I found that very useful, especially when nothing was happening" [P15]. However, fertility data are often not easy to understand [23]. Some participants described doubling down on tracking, tracking multiple measures, and using multiple tracking tools (e.g., P7 used up to 5 apps), hoping more data would lead them to the desired result. For example, P17 reported using multiple devices, including a wrist wearable, an intimate wearable, and a mini microscope to analyze saliva. Every month she wants to add more lifestyle measures, health indicators, and even new devices hoping that at least one of them will help her to conceive: "I don't know that I'll be able to pinpoint it to one thing in particular because I'm trying so many things at once. And I just hope that I'm doing the right thing, because I feel like every month there's some new thing that I wanna try" [P17].

Although these fertility activities and data may be personal and private in nature, they are situated in broader contexts. They are influenced by diverse factors and stakeholders in the whole ecosystem, including partners, healthcare providers, peers, healthcare institutions, social expectations. As P11 explains: "It takes over your whole life. It's something where, even getting up and going to work when you were dealing with recurrent pregnancy loss for three years or something like that and you're supposed to be a productive worker is - that's so hard. I feel like we need support on all levels, like social support, institutional support, emotional support, medical support because I think it's just, we don't recognize the physical and emotional burden" [P11]. To understand the broader context that shapes individuals' fertility experiences and identify ways to alleviate the burdens imposed on them, we use EST as a framework to analyze individuals' fertility experiences. The next sections describe each of the EST layers applied to the context of fertility.

\subsection{Microlayer: Data And Immediate Relationships}

As the EST model suggests, the microlayer encompasses individuals' closer ties: partners, healthcare providers, family \& friends, and peers, who interact with individuals directly. Below we summarize how data is extensively used and shared across the entities of this layer, in different formats and amounts, and at different moments.

6.2.1 Partners: Involved in Fertility Process but not in Data Tracking. Partners are often individuals' closer relationship in the fertility trajectory. Since all our participants were cis women in heterosexual relationships, this section refers to male partners. Trying to conceive is often a couple's shared trajectory that is discussed and agreed by both parts. However, aligned with previous studies' [49], tracking tends to be individual.

Unlike for the female body, there are not many health indicators directly related to male fertility that could be self-tracked at home (e.g., sperm quality can only be analyzed in laboratory), as highlighted by P5: "we've been doing things like basal body temperature and tracking cycle...My wife's. I'm not actually even aware of anything that is useful to track for men. . Most of it is for - it's just for her." Mostly, the only indicators that can be tracked by male partners to improve their fertility and the couple's chances to conceive are lifestyle measures, such as exercise and diet, and medications or vitamins. However, it is often the female partner who track and manage these data: "He was supposed to have lower fat and I was supposed to have higher fat milk. .I just tried to keep track of everything and kept a little schedule going on" [P13].

Tracking female fertility data is also often a task for female only. Among our participants, only one partner (P7's partner) directly engaged in data tracking. By far the most common attitude is to defer to the female partner, because it is her body. Thus, the predominant dynamics is the female partner taking the initiative of tracking and bringing the decisions to be discussed by the couple: "my perception is that he thinks it's my life, it's my body, I have the right to decide when and what to do. We discuss but I never felt that he imposed something or really manifested something. It's on myself. I decide everything basically" [P12].

Although partners may not directly track, they are influenced by tracked data. For instance, P20 and P5 reported being very aware of their partners' tracking activities, describing them in detail and as a joint experience. Moreover, partners need to act upon data results: having intercourse in the fertile window, often having to adapt their schedules and work to accommodate various needs in the fertility process, and supporting their partners through every cycle whatever the results are: "I was more invested, I guess, than he was. Emotionally invested and he was there for me, and with me, and wanted children too, but it wasn't the same kind of emotional investment. So, he was mostly as my support. And a willing and engaged participant" [P14].

Some partners actually dislike tracking, as P20 describes: "She [P19] would show everything to me. And she was very enthusiastic. And somehow, I think I didn't like it very much because it's mechanical...So, I didn't deal with that very well. . .She even tried me to have the apps in my phone, too, but I wasn't very good with them." As he suggests, these differences can create conflicts, which was echoed by his partner, P19: "He wasn't interested at all in my charts and in my fertility data. It was actually like a turn-off for him." However, P19 explained they managed to balance their different engagements with data, and she felt supported by $\mathrm{P} 20$ : "he did support me. He felt different, and it's okay" [P19]. In fact, partners often take this role of emotional support, trying to be stronger for the partner who experiences most of the physical and emotional struggles of fertility tracking and treatments (e.g., "I always tried to be strong for her, so she wouldn't have both of us down" [P20]). However, they can also be as emotionally impacted by tracking results as the female partner: "when it doesn't work, it just makes you feel really down because you have done everything you could, and you have timed it. And then, the period comes. And then, you keep doing that over and over again, it's discouraging" [P20].

6.2.2 Healthcare Providers: Sharing Specific Data to Facilitate Treatments. The second closer relationship in the microlayer is often with healthcare providers, which can vary greatly. Our participants 
described working with OBGYNs, OB nurses, midwives, REIs, traditional Chinese medicine doctors, holistic doctors, fertility acupuncturists, homeopathic specialists, metabolism specialists. As shown in the background, people with fertility challenges often go through a long and complex treatment process from the regular family doctor to specialists such as REIs and going through different treatments.

Data provides a source of cycle information that allows treatment to begin sooner (e.g., "if. . . they don't have any of that information, it sort of delays their evaluation a bit,... because without tracking, they can't really answer that question about their menstrual cycle" [D1]). Providers use specific types of self-tracked data (i.e., "the beginning and the stop dates of their menstrual period. And if they do use LH kits [OPK], the results" [D2]) in the initial consultations to gather patients' medical and fertility history and identify patterns of ovulation.

Data also creates the need for healthcare providers to deal with patients' engagement with data, dealing with their expectations and anxieties. For instance, some individuals take their apps or data spreadsheets to providers. Despite not needing these extensive records, all REIs we interviewed tried to check and help their patients interpret such data: "There's a lot of science behind all of these things that is not common knowledge. And I think without understanding of this, it leads to a lot of anxiety...I try to positively affirm them and then talk with them about what all this [extensive data] means. A lot of what we do is reassurance that this is occurring. Then I talk with them about healthy lifestyle choices, healthy mental habits to protect their mental health" [D4]. When providers do not engage in data interpretation with patients, they may feel discouraged and disengaged. P1, P7, P17, and P21 complained that providers they have seen focused on their age (P1 was too young to face challenges; P7 and P21 too old), or weight (P17), but overlooked their individual experiences that can be demonstrated through their personal data. Then, some individuals use data to try to show providers that there may be other factors they could address: "at my age I don't necessarily believe that doctors will take the specifics of my case seriously...The apps. . help me to demonstrate to them that these aspects of my cycle the apps can track are still viable and I'm still worth taking seriously as a fertility case" [P21].

Finally, data can play a great role in educating individuals about fertility, which may support effective patient-provider collaboration, as described by D5: "It's good to have well-informed patients who understand their body and who are in touch with their physiology. So, I think that these apps can help educate patients very well and they can be very helpful" [D5]). Therefore, data are critical and commonly shared with healthcare providers. Although often patients and providers have different data needs and use data in different ways, their practices complement each other through data.

6.2.3 Family \& Friends: Sharing (Partial) Experiences Over Time. The next role in the microlayer is family \& friends, who interact with individuals closely and influence particularly their emotional experiences. However, they most often do not have access to data, partially because of the sensitivity of the data and stigma. Individuals most often share only experiences, summaries, and high-level issues with their family \& friends, and this sharing evolves with time.
At first, individuals often do not even mention they are trying to conceive and avoid answering questions regarding having children. Some of them consider fertility something very personal that other people do not need to know. With time, when their challenges last longer, individuals often feel the need to tell some people, particularly their families. They tend to share their situations with a few close family and friends without any data. For example, P15 and her partner did not to tell their families in the beginning because they "didn't want to get anybody's hopes up" [P15] because of her endometriosis (diagnosed years before). But over time, they felt they should let them know to avoid questions and comments that could be negative to their personal experience. "When we found out that it really wasn't working, we told both our families. . .once they knew, at least they were more careful about the kind of questions they asked, which made it a little easier. Now, I can call her [mother] to complain about the prices of IVF. It's better now, but that first conversation... you could see in their face they don't even know what to say" [P15]. Similar to P15, individuals' relationship with their family evolve alongside their fertility trajectory, with information being shared gradually in different formats. In addition, P5 (P4's partner) explains that sharing is affected by many factors, including couple's dynamics, their relationship with others, and the fertility experiences of those they share data with: "I've left the decision of whom to share with more in her hands because I feel like emotionally the judging that we would receive - she feels it more keenly...there's just a handful in our family or others we've shared some things with. And to differing extents. Some just, in general, that we have been trying, haven't been able to. Some know that we've tried IVF. And there are some, usually family members, who themselves have gone through IVF, with whom we've discussed the entire process and everything that we've gone through" [P5].

In summary, family \& friends are important relationships in individuals' lives that can influence their emotional experiences in both positive and negative ways. Sharing can become another burden to individuals, especially due to expectations and social pressure.

6.2.4 Peers: Sharing Detailed Data and Experiences. Peers are the last microlevel entity, representing people who face similar challenges, with whom individuals are more open to share. Peers can be "real life" relationships, as in P5's experience described before, or peers from online health communities $(\mathrm{OHC})$ where individuals have no prior relationships. Peers are a central source of information and support and are important for avoiding feelings of isolation. However, because infertility is invisible and entangled with taboos, it is not uncommon that individuals do not know other people experiencing fertility difficulties among their real-life relationships: "I don't think most people really understood what I was going through when I went through it. I had a hard time finding any people with that experience" [P11]. Others know a few peers in person, but because fertility challenges vary a lot, some feel more comfortable turning to online spaces, such as OHCs, where they can find people with similar infertility experiences more easily.

Individuals tend to exchange detailed experiences with peers. Data is often intensely shared in OHCs, especially when participants use the same app to track data and befriend each other in the app, being able to access each other's tracked data, and send personalized 
messages based on the data: "By looking at each other's charts, we knew' 'oh, this person is in the second week of the two-week wait. So, she's probably trying not to pee on a test'... If it was on those sensitive days, we would not say anything like 'oh, are you just dying to take a test.' And after someone got a negative or their period that would be also in the chart. So, we could go and say, 'Oh, I'm sorry you got your period again. This sucks"' [P19]. Some OHCs even organize buddy systems, pairing people with similar situations and facing similar challenges, so they can share experiences, such as personal feelings during treatments: "because a lot of the women found it a little alienating. . .they [OHC] had a survey saying put how old you were, how long you've been trying, what kind of issues you were facing, and they would try to pair you with somebody who was very close to you" [P15].

Although some of our participants found real value in these OHCs (e.g., "I'm on them all the time. It's really helpful" [P18]), not every person experiencing fertility struggles uses them and among the ones that do, some do not post or interact with others much. Others may not like these spaces at all, as P20 described: "I just think that that's very depressing because people just say, oh, I lost it, I lost it again. I'm like, I can't be part of a group like that" [P20]. P17 echoed this feeling, describing she reduced her use of $\mathrm{OHCs}$ in part due to the burnout of "constantly seeing other people's disappointments. . . that are so similar to mine" [P17].

These examples suggest that sharing tracked data can be an important way for individuals to obtain support and information; and sharing data with people who can understand their experiences is critical.

\subsection{Exolayer: Individuals Navigating Organizational Spaces}

Individuals' fertility trajectories do not exist in isolation; they are embedded in social and institutional spaces. In this section we identify three main spaces entangled with fertility trajectories: healthcare, work and life, and technology. Although personal data is not directly shared with the exolayer spaces, the exolayer must be aligned and coordinated with individuals' needs and data practices. These external spaces influence the trajectory work, affecting individuals' emotional experience, and adding various coordination tasks.

6.3.1 Healthcare Space: Financial Cost and Infrastructural Fragmentation. Healthcare is perhaps one of the most important yet fragmented spaces in the exolayer, which requires extensive coordination and management work that need to be aligned with individuals' data practices. Below we summarize the major elements in this space.

Insurance and financial cost - Fertility treatments can impose a huge financial burden on individuals. Generally, the more complex the treatment individuals receive, the more expensive it is, since the treatment may not be covered by insurance or the healthcare system. Many people simply cannot go for clinical treatment because they could not afford it. D5 explained that this context of insurance and cost creates " a demographic gap in access to infertility care. . . Not all insurances cover fertility services and that's a problem. So, we end up selectively seeing the patients who can afford to see us, who are well informed enough to realize that there's a problem and to...make an appointment" [D5]. Echoing D5, P1 described her fears when she experienced financial hardships in her trajectory: " $m y$ first reaction was 'there are no programs for people with low income. . . because they don't want people with low income to have children." Even when insurance or the healthcare system covers the procedures, it can take longer than individuals are willing to (and sometimes can) wait. Facing this reality, those who have financial resources may opt for paying treatments out of pocket because of the time pressure (e.g., P16). Although self-tracking can be a cheaper option when comparing with fertility treatments, (i) it cannot solve all fertility problems and (ii) it can also be costly: "I have spent a good amount of money just on the process of becoming pregnant. I'm really privileged and glad I can do that. I know that a lot of other people can't buy several different pieces of wearable technology for this process" [P17]. The financial burden is so high that participants often described it as a major challenge in their trajectories: "the emotional part. . is exacerbated when it's also a big financial sacrifice... because you have this extra big stake. . because if it doesn't [work], it has bigger implications, or consequences, for the rest of our family life because of our investment in it" [P5]. This financial burden adds pressure to an already complex context in which individuals need to coordinate different organizations with each other and with their cycles and data.

Coordinating and aligning multiple healthcare facilities - Because of the temporal structure of fertility, all the treatments have to be aligned with individuals' menstrual cycles (and thus with individuals' data), otherwise individuals may miss their fertile window and have to wait for the next cycle. For example, P18 described the intense work she had to do to carefully coordinate the multiple steps of her IVF treatment and medical appointments, insurance, and the pharmacy with her fertility cycle: "The whole process moves very quickly... They're pretty much like '... you're gonna be off of it [birth control] this day, you need to start your medication by this time.' And that's a matter of weeks. Sometimes you don't get your calendar for all the appointments until a week before they start. So, you have to call the pharmacy like, 'Hey, just found out I need XYZ medicine.' And they ship it to you, but somebody has to be home to sign for it... And then trying to manage that quick turnaround with my job. . . So, just the quick turnaround is probably the most stressful part" [P18]

Another extreme example of aligning different fragmented healthcare institutions with personal data comes from $\mathrm{P} 4$ and P5. After 6 IUIs that did not lead to full term pregnancy, the couple's best option was IVF. However, they could not afford the costs in the U.S. After intensive research, they decided to do an IVF in Mexico. The coordination work increased since they needed to manage and time different healthcare institutions in different countries with P4's cycle: "We couldn't buy the plane tickets. . . in advance to get cheaper prices because they depended on a test that is done towards the beginning of the cycle. We could only get them a week or two in advance. Or, if we wanted to get them more in advance. . that would cost more because we would need to pay for a hotel there for longer and I would miss more school. . But we just bit the bullet and did the test here, got the plane tickets when we had an idea of when she would be ovulating [based on personal data]...But we were in for a bit of surprise because there were some irregularities with my wife's cycle, 
which hadn't happened ... for a long time. But it made it so that the timing of things wasn't going to work...so, we had to lose our plane tickets" [P5].

Finally, unexpected events can disrupt people's carefully made plans, and require extra management and coordination. This is the case of the COVID-19 pandemic: four out of the seven participants we interviewed during the pandemic described it impacted their fertility plans. For instance, $\mathrm{P} 15$ had planned to do an IVF procedure in a low-cost clinic in New York, far from where she lives. But New York was one of the places most impacted by COVID-19, and P15 does not know if she will be able to travel there: "Now, it's even more stressful because I was really worried about the first endo surgery... and then, it was canceled [due to COVID]. Now, I also have to think about the additional risk of catching the virus. My husband has asthma and lung issues, so I have to be really careful, and now, I just feel like I'm getting older. I know that these things have a time limit and I'm kicking myself for dragging my feet before the virus" [P15].

The healthcare space shapes people's experiences, requiring careful and constant coordination that involves personal data (i.e., timing with the cycle) and their relationships in the microlayer (e.g., their partners and healthcare providers).

6.3.2 Work and Life Spaces: Managing Life Amidst Fertility Challenges. Fertility treatments also involve tremendous resources that go beyond financial costs and distract individuals from their normal life and work, as explained by D4: "it's a significant investment of a couple's resources and the resources of time, energy, emotions, financial, work - away from work, all these different things" [D4]. As this quote surfaces, individuals need to coordinate their fertility cycles with theirs and their partners' work, and with their other activities. For example, when using data to time intercourse, individuals and partners need to act upon the tracking results. P1 told her partner that whenever she gets a positive OPK they would have to find a way to meet: "I just told my then husband that. . . if he is really ready, that we would have to take the opportunity the next time that little symbol comes up. He was at [the University], and I said you will have to bike home, and I'll meet you from the office, and we will just gonna have to do it" [P1].

More complex treatments may interfere with individuals' work and life spaces more since they have to accommodate multiple medical appointments and procedures. P19 described she had to disclose and explain to her boss that she was doing IVF, to justify the work she would have to miss: "thankfully, she was very understanding, but I know that's not always the case" [P19]. In another example, P18 managed to coordinate her work by having extremely early appointments when possible to have the minimum possible impact on her schedule: "I'm lucky in that my clinic offers appointments extremely early in the morning at 6:30 AM and I have to be at work at 7:30. So, the majority of the time I can go to my doctor and be back at work. But some of them are a little bit later than that, so I have to push my schedule a little bit" [P18].

Other aspects of people's lives also influence and are influenced by their fertility trajectory and data practices. For example, P16, who closely monitored hers and her partner's lifestyle measures, explained that they had to change their lifestyles to be "healthier" and save money, avoiding social events, entertainment, and unnecessary expenses: "we have to have a very strict way of life to be the healthiest that we can. . and to not waste money" [P16]. Other life decisions are also entangled in this context. Four of our participants faced the decision of moving countries while trying to conceive, where they would be forced to figure out a new healthcare system under time pressure. P19 and P20 decided to do the IVF before moving from Brazil to the U.S. to use P19's prior "very nice health benefits" [P19], P16 decided to delay the procedure until they settled in the new country (Portugal), and P20 considered returning to her home country (U.S.) from the U.K. but decided not to do it in part because of the COVID-19 pandemic.

The work and life space impacts how fertility trajectories are planned and carried out, and individuals had to carefully make time in their work and life context, consider other stakeholders' work and life (e.g., partner work, travel impact on family members), to accommodate the rather intensive fertility treatments that need to be timed with their cycles.

6.3.3 Technology Space: The Data Industry. With the wide use of fertility technologies, individuals' experiences are increasingly shaped by the data industry, particularly through mobile apps and wearable devices, as well as the media surrounding them. Unlike the other spaces in the exolayer, this space directly connects to personal data tracking. However, in this case data is not shared by the individual: technology companies define how individuals track their data through their products, store their data, and thus affect their fertility trajectories through such influence.

Technology define which health indicators individuals are expected to monitor, as illustrated by P18: "I just...picked the two [apps] that seemed the most highly rated, and whatever they had in there to track, I tracked" [P18]. Technologies also define who can track and access the data. For example, P21 argued that even if her partner desired to analyze her data, he would not be able to: "the app on the phone, it's not something that he can get too into because he can't just be curious and then go see it because it's not posted anywhere" [P21]. The only partner that was actively involved in data tracking did it manually: "he physically writes it down, and there's some code that he does" [P7]. As these examples show, the design of tracking technologies can impose more burden on individuals and even influence them to track more.

Technology also adds limitations on how fertility data can be analyzed. P9, P11, P17, and P21 described they had to manually copy data from wearables or apps to spreadsheets, so they could do different analysis that the original device did not allow, or to other apps, so they could combine data from different apps to do more analysis. However, such efforts were not easy: "It's not transferable, the data in the app. You cannot get the conclusion from the app, but it's not easy to export the data to any other software" [P9].

In addition to shaping how individuals collect and analyze their personal data, fertility tracking technologies also aggregate data in ways that can reinforce certain standards back to individual users: "they have some models based on. . data from many users...they have points that they'll give you out of 100, of pregnancy indicators which are based on your own indicators and other people's indicators" [P21]. As P21 experienced, such features may help users to better understand their data that can be difficult to interpret on their own. However, often there is not enough information to show how these 
calculations are made and how valid they are, which can potentially lead to more stress and anxiety.

All these influences are entangled with technology companies' economic interests. Such companies often offer paid versions of their apps or other integrated products such as OPK strips that work with the app (e.g., "[app] sells its own strips" [P17]) or secondary apps (e.g., "they push you into some sort of pregnancy version of their app" [P21]). Some of our participants (P7, P13, P17) described finding out about the tracking technologies they acquired through advertisements in social media, such as Facebook, Instagram, Pinterest, or in television shows: "a Facebook ad. And that was the first thing that really introduced me to the world of tracking" [P17]. Similarly, P7 reported an experience of discovering a fertility-related product randomly: "I ordered something for my labor. . . and Amazon was like, 'based on your purchase of this, you may wanna also buy this.' And it was a spray bottle for the bathroom. No one had told me that after delivery, I wasn't gonna be able to wipe myself. . Like, of course, that makes perfect sense. But why is Amazon telling me this? Why didn't anybody in the class tell me?" [P7]. It is not necessarily P7's case, but this quote suggests that lack of knowledge about fertility may influence individuals to purchase products following companies' economic interests.

Finally, the marketing of tracking technologies may imply that tracking increases pregnancy chances and that if individuals act on the fertile window predicted by the app, pregnancy is guaranteed. Such misperception can lead to increased disappointment when people do not conceive: "People think that the chance of conception if you have sex during the fertile window. . is $100 \%$. So, if it's not happening for them, something's wrong. . that's where the apps come in. . In the beginning I think it reduces anxiety, because it makes them feel in control. But then it becomes, actually, an anxiety in and of itself and an obsession. And I see that quite a lot" [D4].

In summary, the pervasive use of fertility technology makes it a unique space that influences, defines, and dictates how fertility data are used and fertility related activities are performed. The influences on data practices are profound and can further reshape people's daily activities, their interactions with others, and their engagement with other institutional spaces.

\subsection{Macrolayer: Broader Societal Influences}

The macrolayer refers to overarching societal contexts, such as ideological, cultural, economic, and political systems, that affect and are manifested in all the other layers. Due to the demographics of our participants, our data speaks about cis heterosexual women mostly in the U.S. or western contexts. Our study found many societal forces influencing individuals' fertility trajectories. The main ones are knowledge about female fertility and body, and social expectations of gender. These forces shape the context in which individuals use self-tracking and their personal data.

6.4.1 Knowledge about Female Fertility and Body. Fertility education and knowledge about the female body were discussed by most participants (individuals, partners, and healthcare providers). The lack of knowledge about female fertility leads people to look for other sources of information, particularly online. Although such spaces can be a great source of fertility information and support, misinformation is a common risk (e.g., "people were claiming that a gel helped the sperm to survive better and move quicker. I almost bought it, but I talked to a doctor and he said, '... we have to be careful, because sometimes those gels. . can actually damage and kill more sperm than help" [P4]). Some participants also mentioned "it was just a little bit of information overload" [P17] when they looked for fertility information online. D4 highlighted how media plays a role in spreading misinformation: "People have seen movie stars get pregnant at 45, 50 years old...Conscientious public figures will say 'this was done with a donor egg.' Or, 'this was done with eggs I had frozen in my early 30s.' But oftentimes the public figure is not conscientious like that, and she says, 'I got pregnant with my own eggs at 45 or 48.' And so, couples come in thinking, 'well, I'm 48. Let's get pregnant with my own eggs.' And that's just not possible" [D4].

Many participants reported that the lack of knowledge of how common infertility and fertility-related events (e.g., miscarriages) are increases their feelings of isolation and inadequacy. For instance, P7 uses herself as an example of how even highly educated women do not know enough about their bodies: "All this information really could have been taught to me much younger, and it would have been much less confusing... Women specifically are not taught enough about their bodies... Why didn't anyone teach me about my mucus? All these years, you're like, 'What's in my underwear? I don't know. Whatever. Is it an infection? Whatever" [P7]. P19 described a similar but more severe experience: her extremely painful periods were only taken seriously when she was diagnosed with infertility, suggesting that female bodies and experiences may be more easily neglected when the complaints are not directly related to pregnancy: "I was the textbook case for endometriosis since my first period when I was 12. . My cycles were 8 days long. I had really awful pain. . [that] didn't get better with medicine, even though every time I went to an OBGYN they would say 'you just have to take this one'... After I was sexually active, I had pain during intercourse. I had everything. . And it wasn't until I was diagnosed with infertility that someone took me seriously like - she is really in pain. After a while, I just started believing that it was all in my head and that I was just weak. Because people, even doctors, kept telling me 'no, your pain is normal. Every woman goes through that. It's just what it is.' And now I know that it's not the normal way. . But I was just neglected for almost 20 years" [P19].

Although our participants think knowledge about the female body should be more widespread ("I think it's a public health concern that should be taught more, even in school" [P19]), many of them believe that the use of tracking technologies and personal data is an opportunity to learn more about their bodies, a thought also echoed by the healthcare providers we interviewed. P13 builds on this thought and adds that such technologies can help in normalizing fertility experiences: "as the [tracking] technology continues to improve and becomes more mainstream, I think people will just inherently understand more about how everything goes as has happened kind of in other areas. And then, it will be an easier topic to talk about because more people will be knowledgeable" [P13].

This lack of knowledge about female fertility and bodies is connected with historical taboos [1], reinforces such taboos, and plays a role in existing social expectations of gender, as described next.

6.4.2 Social Expectations of Gender. Conception is strongly entangled with social expectations of gender. Pregnancy and motherhood 
are still seen as women's role and strongly entangled with what it means to be a woman. Many women internalize these beliefs and, as D4 argues, "much of their self-identity is wrapped up in this idea that women are fertile, and providing a baby, and having that ideal family" [D4]. In fact, many participants stated that facing challenges to conceive made them feel "defective" [P14], "incomplete" [P12], or not "working right" [P1]. Such negative feelings are internalized oppressions [61] commonly fed by media, as well as by other people's expectations.

Because such expectations are so widespread and infertility is still so stigmatized, people reproduce these beliefs in such a way that put the blame on the person having challenges (e.g., "I was frustrated with family members who didn't understand and thought we were doing it wrong or something" [P14]). And although "infertility is a couple's disease" [D4], this pressure is often placed mostly on women. D5 even commented that although male factors for infertility are not uncommon, sociocultural beliefs about gender can interfere in treatments: "in some cultures the males think that it's always the female's fault and they might even refuse to even get a semen analysis and they might say, 'Oh, this is not my problem"' [D5]. Although our participants did not experience conflicts as serious as these with their partners, they were still the ones responsible for all the self-tracking activities, including managing their partners' lifestyle measures.

Although our sample was not significantly diverse, individuals described cultural expectations on pregnancy, for example, in Hispanic ("they're... Hispanic families. . in my family, in my culture, it's very normal. I'm very old [33 years old] for my culture for not having a kid yet" [P15]), Chinese ("my in-laws, definitely, they can't accept that [not having kids] - for Chinese parents, that's very normal" [P9]), and U.S. mid-western cultures ("I'm from the Midwest where people tend to get married and have families younger...It seemed to make sense in my neatly laid-out Midwestern plan" [P11]). Although these are different cultures, they revealed similar expectations towards pregnancy (i.e., essential, early) which indicates that some ideologies are bigger than specific cultural influences and may be related to gender expectations in general.

Finally, conception expectations are also entangled with education, work, and other life decisions. Many women are delaying pregnancy to pursue education and a career, but the plan (and the pressure) of conceiving remains. D4 explained that this sociocultural context increases the pressure for conceiving in a short window of time, which may not be currently possible: "The [childbearing] age in the U.S. has been pushed back by 4 years. . And that's to pursue careers, pursue education, find the ideal partner, what have you. So, that by the time we're ready to conceive... there's already this sense of stress that they know they're older. They know they've waited. And so, it has to happen right now. And it doesn't work that way" [D4]. The shorter the window of time the more important access to fertility treatments may become. However, as described in the exolayer section, such treatments are often very expensive and not covered by healthcare insurances.

These aspects of the macrolayer influence data and practices through internalized socio-cultural values and biases that can influence how individuals interact with technologies or even be reproduced in technology design. In summary, as the results show, individuals' fertility trajectories are bounded and shaped by their relationship with others, the institutional and technological spaces they are part of, and the broader societal context. These factors generate additional work for individuals who track data and manage the painful experience of (in)fertility.

\section{DISCUSSION}

Based on our findings, we first describe the specificities in the fertility ecological model related to fertility data and temporalities. We then discuss how these unique characteristics, allied with the influence from out layers, make this a challenging context for the individual in the center of this ecology. Such context demands individuals to perform intense data work across multiple layers in the model with the constant pressure of time. Finally, we discuss opportunities to influence broader layers through personal data collected by individuals.

\subsection{An Ecological Model of Fertility Data Practices}

Figure 1 presents a model of EST applied to fertility data practices. This ecological perspective is suitable and critical for the fertility context for multiple reasons. First, it highlights the relations between the individual whose body is primarily tracked, their partners, healthcare providers, peers, and family \& friends, and how data influence and are influenced by these relationships. Second, it recognizes the work of managing different organizations that need to be coordinated with individuals' fertility cycles and, thus, with their data. It also highlights the influence of the technology industry in defining, supporting, and limiting people's data practices. Finally, this perspective surfaces how these layers are influenced by the larger societal contexts in which individuals' experiences and related data practices are situated.

These multiple layers of influence have always existed, but the increasing use of self-tracking data impact the interactions between them and the individual. Fertility data are private and individually

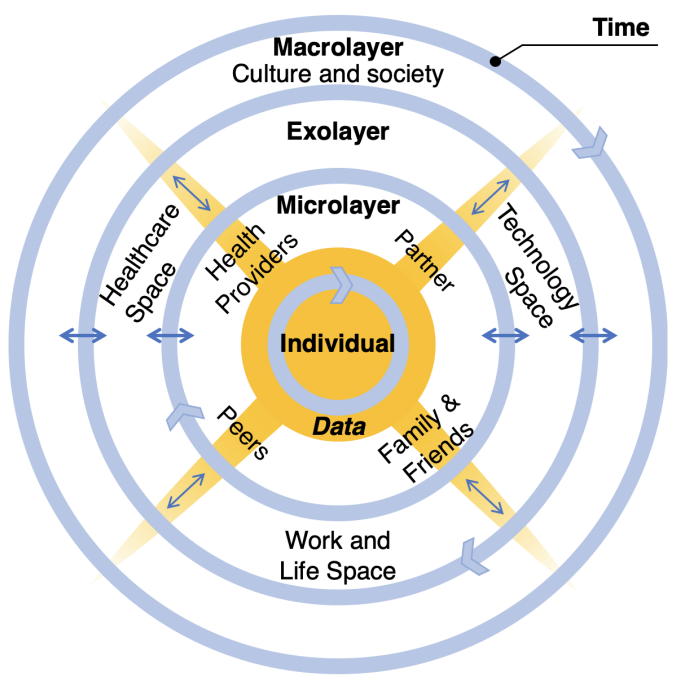

Figure 1: Bronfenbrenner ecological model $[14,15]$ applied to fertility 
collected but shared to and influenced by other layers, which is represented in Figure 1 by the yellow highlight surrounding the individual and overflowing to the other layers. The color fades to symbolize that data are used more intensively in the inner layers but influence and are influenced by the outside layers.

Previous research using EST have explored how technology can support different relationships [6, 55, 104], but did not directly approach technology and data as mediators of these interactions. Inspired by Murnane et al. [75], we use the EST model to analyze the influence of personal self-tracked data. Our findings suggest that the influence of data is much more structured and intense in the fertility context when compared to other ecologies of care contexts $[35,60,75]$. This is partially due to the expectation of action present in fertility $[64,69]$, which is seen as a way to directly control the results of their fertility trajectories [23]. Thus, individuals engage in intense self-tracking activities [22], which influence and guide their interactions with stakeholders in the microlayer and institutions in the exolayer.

Another unique influential factor in the ecological model of fertility is time. Prior research using the EST often describe time as an overarching layer representing changes in time or transitions that impact individuals $[15,75]$. While our study identifies this influence as well, time plays more direct and diverse roles in fertility. Time works both as a structure and as a pressure: it structures all the activities an individual needs to perform (e.g., all layers need to be timed with menstrual cycles' temporalities), under the pressure of time, since pregnancy chances reduce over time and with age [92] For this reason, we represented time as multiple temporal circles surrounding the original EST layers, symbolizing the multiple temporalities involved in fertility trajectories and how they relate to and influence each layer, including cycle temporalities (e.g., length of the cycle, ovulation, and fertile window) and the pressure of time around the individual, the differences in data tracking and sharing around the microlayer, the influence of time on individuals' interactions with different institutions that need to be coordinated with their cycle around the exolayer, and the transitions and changes in sociohistorical conditions that influence individuals' lives around the macrolayer.

\subsection{The Influence From Outer Layers On Individuals' Data Practices}

Although data practices in fertility are individual oriented and fertility data are often not shared and used beyond the microlayer, there are profound influences from the outer macrolayer on individual's data practices at the center. The macrolayer influences the other layers through cultural and societal ideologies that are embedded in institutions, technologies, relationships, and practices that produce, use, and influence data. Such connection may be subtle, but it has much lasting influences and takes time to change.

As described in the findings, the social forces in the macrolayer directly and indirectly influence the experiences of the individual in the center of the fertility model. They shape and influence both the knowledge about the body (that fertility is private and a social taboo) and the expectations of gender (that females are expected to reproduce). Because of these historically formed societal influences, our findings show that many individuals had to learn about fertility knowledge and fertility technologies through advertisements they encountered randomly on social media. Without appropriate knowledge about fertility, individuals may be more vulnerable to market influences, and more likely to be affected by misinformation about fertility. Technologies and media may also reinforce unrealistic and idealized fertility goals and experiences, reproducing and reinforcing societal values and biases. When these goals are not achieved, individuals may experience increased stress and disappointment. Some may further question their identity (in this case as women) and keep working with data in a trapped engagement hoping that something will work [22]. Lupton [69] describes sexual and reproductive self-tracking apps portray women as "reproductive subjects," reinforcing some of the gender stereotypes we encounter in our data. Similarly, Epstein et al. [33] describe how menstrual apps assume the gender and sexuality of individuals and their partners. Thus, these technologies may limit individuals' experiences, their data collection and analysis possibilities. Thus, societal influences may be brought into design of technologies and then indirectly influence individual's data practices through these technologies.

Societal influence, including the political and economic policies and ideologies, also shapes the healthcare system in the exolayer and how individuals are expected to deal with their own health. Countries like the U.S. (where most of our participants were located) do not have universal healthcare coverage, and among the ones that do, many do not cover infertility treatments (e.g., U.K.). This lack of support adds to neoliberal views of healthcare that promote a high level of individualization of health and put the responsibility to be "healthy" on the individuals instead of providing institutional support to them $[38,45,86]$. Under such views, persistent action is praised while doing "nothing" is seen as a failure [12]. Self-tracking technologies and data arise in this context, often embedded in "techno-utopian discourses" that emphasize the potential benefits of technology for patient empowerment [68]. Individuals then have the moral responsibility to engage in data practices and act towards their health goals, in our case towards conception. The narratives of self-responsibility and the belief that persistent action ultimately leads to individuals' goals (i.e., conceiving) directly influence individuals to engage in more data work $[12,22]$. Such narratives may also reinforce feelings of guilt, leading individuals to double down on tracking or to blame themselves for not conceiving. As Homewood et al. [50] describe, internalized socio-cultural values and biases also play out on how individuals interact with technologies. So, technologies not only reproduce societal influences, but the ways in which individuals use and engage with them also reflect the cultural and societal context in which individuals are embedded [50]. So, the macrolayer societal factors exert their influences through infrastructure of healthcare systems and through leading to increased data practices by individuals.

Other societal influences were not very apparent in our data due to the representativeness of our sample, which did not include individuals from some minoritized populations [52], such as Black, Indigenous, and LGBTQ+ people. While our data show clear influence of gender stereotypes, such influences may be different and interconnected with other social dimensions for individuals from these populations [25, 52]. For instance, infertility studies [43, 52] show that the isolation and loneliness African-American women experience during their fertility trajectories have strong racial and 
cultural components: they are reinforced by stereotypes about their sexuality and the public image of infertile couples as white. People with low social-economic status often do not have access to infertility treatments (as described by D5) and may be more often directed towards contraception than to assisted reproduction (as lived by P1), reproducing negative stereotypes of hyper-fertility and sexual irresponsibility [43]. Technology and data can reinforce such stereotypes as well $[39,47,86]$ and even increase health disparities [100].

\subsection{The Data Work Of Individuals}

One aspect that was clear in our data is the intense and multifaceted work individuals do during their fertility trajectories across multiple layers of the ecological model. Previous research has discussed different types of patient work, such as illness trajectory work, everyday life work, and biographical work [21], uncertainty abatement work [101], sentimental work [95], and infrastructuring work [45]. We found evidence of individuals performing all these types of work in their trajectories. We also found that data work influences, merges, entangles, and shapes many of these activities.

Bossen et al. [13] define data work as "any human activity related to creating, collecting, managing, curating, analyzing, interpreting, and communicating data." Our findings show that individuals conduct intense data work in two main ways: their direct work with data and their work influenced by data. First, individuals use data individually to understand their own fertility cycles, particularly their temporalities (e.g., ovulation day, fertile window, two-week wait time [23]). Data work is also present in their relationships and interactions with others, particularly with partners, who have to take actions based on the data. Extending previous studies' results [49], we found that although conceiving is a shared goal, individuals were not only responsible for all female tracking activities, they were also often responsible for managing their partners' lifestyle data and guide couples' main decisions. These activities add to individuals' data work, which also includes the data work related to their relationships with healthcare providers, who need some of individuals' data to inform their own work, and peers, who can provide support in making sense of the data [23]. It can be an intense daily work, which is often shaped by the technologies individuals use $[13,49]$.

Data work is often facilitated and structured by technology, particularly mobile apps and wearables, which support and impose what to do, when, and in which order [13]. In fact, what is considered fertility data is almost (re)defined by technology (e.g., what bodily measures can be tracked, which data can be stored, what data analysis can be done) [39]. However, when their needs are not fully supported, individuals in our study had to manually copy data from apps to do more analysis or to cross examine data from multiple devices. In addition, how data can be shared is most often not individuals' choice but defined by the fertility technology. When the data cannot be easily shared (e.g., the partner is not a default user of a fertility app), often times individuals have to copy the tracked data out of the technologies, curate the data to an appropriate format, then share them to the stakeholders they wish to benefit from the data. These are added data work imposed by technology.
The second form of data work plays out through the coordination activities centered in fertility data. As our findings show, individuals need to coordinate multiple organizations, overcoming different breakdowns and allocating their time, effort, energy, financial, and emotional resources to maintain a balance between different aspects of their lives and the demands of their fertility treatments [21]. All these activities need to be coordinated with the temporalities of individuals' cycles and, consequently, with their data (i.e., it is often through their data work that they identify their cycle phases). As the findings show, everything needs to be carefully aligned together and mapped out following the cycle time, which creates a significant amount of work that is influenced by and related to fertility data.

Unlike the direct data work that can be assisted fully or partially by technology, the second form of indirect data work is seldom supported by technologies. Coordinating, aligning, anticipating and allocating work is often referred to as articulation work in Computer Supported Cooperative Work [97]. Such work is characterized as complex, burdensome, invisible and difficult to be automatized. For instance, fertility apps do not help individuals to coordinate their cycle time, work schedule, life commitments, and treatment time. Even if they did, it would still be individuals' task to pull and put the different times into the apps. As such, this work is often imposed on individuals as a form of invisible work [94] that contributes to the underestimation of individuals' burden [102] and to infertility's double invisibility: the invisibility of the condition and of its painful consequences, reinforcing feelings of disenfranchised grief [72].

In summary, these data work and work around data can be intense and are often enforced on individuals through the multiple layers of influences we identified in the ecological model. This work is also often performed by individuals alone, imposing significant physical and emotional burden that adds on the existing stress of infertility.

\subsection{The Data Influence from Inside Out}

The ecological analysis shows clear influences and impacts from the outside layers to the individual data practices inside. Although it may seem that individuals have to obey the societal norms, face the institutional constraints, follow the guidance of technology design, in our study, we also found cases that suggest that the data and data practices from the center of the model can act inside out to influence the outside layers. First of all, all our participants (individuals, partners, and healthcare providers) appreciated the positive aspects of data tracking. None of them described tracking and technologies as inherently negative. Our study shows that data and technology can enable individuals to learn about their bodies and gain more fertility knowledge, make the internal fertility processes "visible" [86], and provide individuals a sense of control over their bodies and fertility experiences [7, 16, 22]. Similar to previous studies in rare and invisible conditions [27, 36, 70], our participants also described occasions where they used data as advocacy to raise fertility awareness to the public. Besides, although technology and data have the power to define what is fertility data and how such data should be tracked, individuals do not simply comply with technology suggestions or impositions [39, 86]. For example, some of our participants circumvented the limitations of fertility technologies by actively copying data from one technology 
to others to perform comparisons and further analysis. Therefore, as represented in the model, data can also be used to influence the outer layers. Below we discuss a few open suggestions on bringing the data influence inside out through technology design.

On the individual and microlayer: technology could support data ownership and multiple personal [39] and shared [36, 70] uses of data. It could allow different and evolving relationships with data, both for the individual facing challenges (supporting the different fertility temporalities, such as life stages and treatment) and for the other stakeholders they need to interact with in their fertility trajectories. For example, designers and researchers could explore designs that go beyond utility, efficacy, and accuracy (e.g., Ovum $[48,49])$ or investigate how to reduce the burden these activities may impose on individuals. Fertility tracking technologies could also engage more with partners, not only allowing individuals to share data (if they desire), but also supporting partners in playing a more active role in the fertility trajectory, by, for instance, offering information about their own fertility, allowing tracking their own lifestyle data, and supporting partners in managing exolayer influences and helping to coordinate the interactions with different healthcare institutions. Partners' inclusion, particularly male partners, can also tackle the broader societal pressures, such as expectations about gender, and relieve the burden of data work on individuals. Different levels of disclosure [36] that are personalizable, modifiable $[67,75]$, and that support a "slow discovery process" [70] (allow others to slowly transition from gaining awareness to understanding how to be helpful) could help in expanding individuals' care network and potentially reducing their burden. Sharing data could also help individuals to find peers to gain support and ease the emotional burden, especially for those who are not currently on online communities. Our participants described enjoying the "cycle buddies" programs in the OHC, so fertility tracking technologies could replicate these experiences. These interactions with peers, family, and friends can also indirectly influence macrolayer aspects such as the lack of knowledge about fertility. Finally, technology could better bridge patients' and providers' different data practices, supporting providers to identify the information they need and supporting patients to emphasize the personalized aspects of their fertility trajectories that may need providers' deeper attention [24].

On the exo and macrolayer: data can be a powerful tool to influence organizational design and cultural perceptions. First, data from individuals can act up to reveal the prevalence of infertility cases, the struggles individuals experience, the challenges they encounter in seeking health services, and the various burden they face. As Ruckenstein and Schüll [86] suggest, self-tracking data can have social and political impacts if used to showcase health inequalities, by for example, showing that negative experiences are tied to societal norms and pressures and not to individual characteristics and personal actions. Fertility data can be valuable and powerful to influence health policy and organizational design that direct impact people's fertility experiences (e.g., [76]). For instance, initiatives such as data feminism [29] and Data for Black Lives [105] have proposed the use of data science to challenge power inequalities and benefit marginalized populations. Other initiatives like the Citizen Endo [31] create a citizen science community to support research through individuals' personal data, which can help in identifying symptoms and experiences related to endometriosis, an enigmatic disease related to female fertility [73]. Such data-driven initiatives can exert the influence from inside out. In addition, although many of our participants described tracking as a means to learn about their bodies, most current fertility tracking tools are not designed with the goal of educating their users [34]. Fertility tracking technologies could explore the ways of using personal data to foster learning experiences. Promoting fertility education on a large scale can make infertility experiences more visible to the public and lead to more structural changes in the outer layers. Fertility education can also include learning about the complicated social relationships involved in fertility experiences. As suggested by our participants, their interactions with others and their work across layers would be easier if more people were knowledgeable about infertility experiences. Finally, changes on the outside layers take time, as the sociocultural perceptions are formed historically, but data may help in this process. Frameworks such as the EST can be also useful in self-tracking and HCI research to identify breakdowns that can be tackled by technology and aspects that technology cannot (or should not) approach (e.g., imposing more "self-responsibility" and work on the individual).

\section{CONCLUSION}

Fertility data are often seen as private and restricted to the individual level, but (in)fertility experiences are embedded in broader ecologies of care, that include their close relationships, the relations between personal and institutional spaces, and larger and overarching sociocultural contexts. We interviewed 21 people facing challenges to conceive and five healthcare providers specialized in infertility, using the Ecological Systems Theory to investigate (in)fertility experiences with data. We described how fertility data influence and are influenced by varied stakeholders, institutional contexts, and sociocultural factors. We then discussed how fertility unique characteristics and temporalities, allied with the influence from out layers, make this a challenging context for the individuals in the center of this ecology, who need to perform intense data work and work around data to manage all these layers of influences. Finally, we discussed opportunities to use data to counterinfluence the outmost layers from the inside out.

\section{ACKNOWLEDGMENTS}

This work was supported in part by the 2020 Microsoft Dissertation Grant from Microsoft Research and the 2020 Exploration Award from the University of California, Irvine Donald Bren School of Information and Computer Science.

\section{REFERENCES}

[1] Teresa Almeida, Rob Comber, and Madeline Balaam. 2016. HCI and Intimate Care As an Agenda for Change in Women's Health. In Proceedings of the 2016 CHI Conference on Human Factors in Computing Systems (CHI '16), 2599-2611. https://doi.org/10.1145/2858036.2858187.

[2] Teresa Almeida, Rob Comber, Gavin Wood, Dean Saraf, and Madeline Balaam. 2016. On Looking at the Vagina through Labella. In Proceedings of the 2016 CHI Conference on Human Factors in Computing Systems (CHI '16), 1810-1821. https://doi.org/10.1145/2858036.2858119.

[3] Jessica S. Ancker, Holly O. Witteman, Baria Hafeez, Thierry Provencher, Mary Van de Graaf, and Esther Wei. 2015. "You Get Reminded You're a Sick Person": Personal Data Tracking and Patients With Multiple Chronic Conditions. Journal of Medical Internet Research 17, 8: e202. https://doi.org/10.2196/jmir.4209. 
[4] Nazanin Andalibi. 2020. Disclosure, Privacy, and Stigma on Social Media: Examining Non-Disclosure of Distressing Experiences. ACM Transactions on Computer-Human Interaction (TOCHI) 27, 3: 1-43.

[5] Nazanin Andalibi and Andrea Forte. 2018. Announcing Pregnancy Loss on Facebook: A Decision-Making Framework for Stigmatized Disclosures on Identified Social Network Sites. In Proceedings of the 2018 CHI Conference on Human Factors in Computing Systems (CHI '18), 158:1-158:14. https://doi.org/10.1145/ 3173574.3173732

[6] Rosa I Arriaga. 2017. Using an ecological systems approach to target technology. Autism Imaging and Devices: 419.

[7] Amid Ayobi, Paul Marshall, Anna L. Cox, and Yunan Chen. 2017. Quantifying the Body and Caring for the Mind: Self-Tracking in Multiple Sclerosis. In Proceedings of the 2017 CHI Conference on Human Factors in Computing Systems (CHI '17), 6889-6901. https://doi.org/10.1145/3025453.3025869.

[8] Madeline Balaam, Rob Comber, Ed Jenkins, Selina Sutton, and Andrew Garbett. 2015. FeedFinder: A Location-Mapping Mobile Application for Breastfeeding Women. In Proceedings of the 33rd Annual ACM Conference on Human Factors in Computing Systems (CHI '15), 1709-1718. https://doi.org/10.1145/2702123. 2702328.

[9] Andrea M. Barbarin, Predrag Klasnja, and Tiffany C. Veinot. 2016. Good or bad, ups and downs, and getting better: Use of personal health data for temporal reflection in chronic illness. International Journal of Medical Informatics 94: 237-245. https://doi.org/10.1016/j.ijmedinf.2016.06.011.

[10] Jeffrey Bardzell, Shaowen Bardzell, Amanda Lazar, and Norman Makoto Su. 2019. (Re-)Framing Menopause Experiences for HCI and Design. In Proceedings of the 2019 CHI Conference on Human Factors in Computing Systems (CHI '19), 115:1-115:13. https://doi.org/10.1145/3290605.3300345.

[11] Gay Becker. 1994. Metaphors in Disrupted Lives: Infertility and Cultural Constructions of Continuity. Medical Anthropology Quarterly 8, 4: 383-410. https://doi.org/10.1525/maq.1994.8.4.02a00040.

[12] Gay Becker and Robert D. Nachtigall. 1994. 'Born to be a mother': The cultural construction of risk in infertility treatment in the U.S. Social Science \& Medicine 39, 4: 507-IN2. https://doi.org/10.1016/0277-9536(94)90093-0.

[13] Claus Bossen, Kathleen H Pine, Federico Cabitza, Gunnar Ellingsen, and Enrico Maria Piras. 2019. Data work in healthcare: An Introduction.

[14] Urie Bronfenbrenner. 1977. Toward an experimental ecology of human development. American psychologist 32, 7: 513.

[15] Urie Bronfenbrenner. 1992. Ecological systems theory. Jessica Kingsley Publishers.

[16] Adrian Bussone, Simone Stumpf, and George Buchanan. 2016. It Feels Like I'm Managing Myself: HIV+ People Tracking Their Personal Health Information. In Proceedings of the 9th Nordic Conference on Human-Computer Interaction (NordiCHI '16), 1-10. https://doi.org/10.1145/2971485.2971542.

[17] Nadia Campo Woytuk, Linette Nilsson, and Mingxing Liu. 2019. Your Period Rules: Design Implications for Period-Positive Technologies. In Extended Abstracts of the 2019 CHI Conference on Human Factors in Computing Systems (CHI EA '19), LBW0137:1-LBW0137:6. https://doi.org/10.1145/3290607.3312888.

[18] Nadia Campo Woytuk, Marie Louise Juul Søndergaard, Marianela Ciolfi Felice, and Madeline Balaam. 2020. Touching and Being in Touch with the Menstruating Body. 1-14.

[19] CDC. NSFG - Listing I - Key Statistics from the National Survey of Family Growth. Retrieved March 15, 2019 from https://www.cdc.gov/nchs/nsfg/key_ statistics/i.htm.

[20] Chia-Fang Chung, Kristin Dew, Allison Cole, Jasmine Zia, James Fogarty, Julie A Kientz, and Sean A. Munson. 2016. Boundary Negotiating Artifacts in Personal Informatics: Patient-Provider Collaboration with Patient-Generated Data. In Proceedings of the 19th ACM Conference on Computer-Supported Cooperative Work \& Social Computing (CSCW '16), 770-786. https://doi.org/10.1145/2818048 2819926.

[21] Juliet Corbin and Anselm Strauss. 1985. Managing chronic illness at home: three lines of work. Qualitative sociology 8, 3: 224-247.

[22] Mayara Costa Figueiredo, Clara Caldeira, Elizabeth V. Eikey, Melissa Mazmanian, and Yunan Chen. 2018. Engaging with Health Data: The Interplay Between Self-Tracking Activities and Emotions in Fertility Struggles. In Proc. ACM Hum. Comput. Interact. https://doi.org/10.1145/3274309.

[23] Mayara Costa Figueiredo, Clara Caldeira, Tera L. Reynolds, Sean Victory, Kai Zheng, and Yunan Chen. 2017. Self-Tracking for Fertility Care: Collaborative Support for a Highly Personalized Problem. Proc. ACM Hum.-Comput. Interact. 1, CSCW: 36:1-36:21. https://doi.org/10.1145/3134671.

[24] Mayara Costa Figueiredo, H. Irene Su, and Yunan Chen. [forthcoming]. Using Data to Approach the Unknown: Patients' and Healthcare Providers' Data Practices in Fertility Challenges. Proceedings of the ACM on Human-Computer Interaction, $\mathrm{CSCW}$

[25] Kimberle Crenshaw. 1997. Mapping the margins: Intersectionality, identity politics, and violence against women of color. The legal response to violence against women 5: 91.

[26] John W. Creswell. 2007. Qualitative inquiry and research design: Choosing among five approaches, 2nd ed. Sage Publications, Inc, Thousand Oaks, CA, US
[27] Tabby Davies, Simon L. Jones, and Ryan M. Kelly. 2019. Patient Perspectives on Self-Management Technologies for Chronic Fatigue Syndrome. In Proceedings of the 2019 CHI Conference on Human Factors in Computing Systems (CHI '19), 1-13. https://doi.org/10.1145/3290605.3300452.

[28] Catherine D'Ignazio, Alexis Hope, Becky Michelson, Robyn Churchill, and Ethan Zuckerman. 2016. A Feminist HCI Approach to Designing Postpartum Technologies: "When I First Saw a Breast Pump I Was Wondering if It Was a Joke." In Proceedings of the $2016 \mathrm{CHI}$ Conference on Human Factors in Computing Systems (CHI '16), 2612-2622. https://doi.org/10.1145/2858036.2858460.

[29] Catherine D'Ignazio and Lauren F Klein. 2020. Data feminism. MIT Press.

[30] Xianghua Ding, Yunan Chen, Zhaofei Ding, and Yiwen Xu. 2019. Boundary Negotiation for Patient-Provider Communication via WeChat in China. Proceedings of the ACM on Human-Computer Interaction 3, CSCW: 1-24.

[31] Noémie Elhadad, Adrienne Pichon, Sharon Gorman, and Emma Horan. Welcome to Citizen Endo. Retrieved September 14, 2020 from http://citizenendo.org/.

[32] Jane Elliott. 2020. Using Narrative in Social Research. . SAGE Publications Ltd, London. https://doi.org/10.4135/9780857020246.

[33] Daniel A. Epstein, Nicole B. Lee, Jennifer H. Kang, Elena Agapie, Jessica Schroeder, Laura R. Pina, James Fogarty, Julie A. Kientz, and Sean Munson. 2017. Examining Menstrual Tracking to Inform the Design of Personal Informatics Tools. In Proceedings of the 2017 CHI Conference on Human Factors in Computing Systems (CHI '17), 6876-6888. https://doi.org/10.1145/3025453.3025635.

[34] Jordan Eschler, Amanda Menking, Sarah Fox, and Uba Backonja. 2019. Defining Menstrual Literacy With the Aim of Evaluating Mobile Menstrual Tracking Applications. Computers, informatics, nursing: CIN. https://doi.org/10.1097/ CIN.0000000000000559.

[35] Hayley Evans, Udaya Lakshmi, Hue Watson, Azra Ismail, Andrew M Sherrill, Neha Kumar, and Rosa I Arriaga. 2020. Understanding the Care Ecologies of Veterans with PTSD 1-15.

[36] Sergio Felipe, Aneesha Singh, Caroline Bradley, Amanda CdeC Williams, and Nadia Bianchi-Berthouze. 2015. Roles for Personal Informatics in Chronic Pain. In Proceedings of the 9th International Conference on Pervasive Computing Technologies for Healthcare (PervasiveHealth '15), 161-168. Retrieved October 4, 2018 from http://dl.acm.org/citation.cfm?id=2826165.2826189.

[37] Natasha Felizi and Joana Varon. 2016. MENSTRUAPPS - How to turn your period into money (for others). Retrieved July 24, 2019 from https://chupadados.codingrights.org/en/menstruapps-como-transformar-suamenstruacao-em-dinheiro-para-os-outros/.

[38] Aristea Fotopoulou and Kate O'Riordan. 2017. Training to self-care: fitness tracking, biopedagogy and the healthy consumer. Health Sociology Review 26, 1: $54-68$.

[39] Sarah E. Fox, Amanda Menking, Jordan Eschler, and Uba Backonja. 2020. Multiples Over Models: Interrogating the Past and Collectively Reimagining the Future of Menstrual Sensemaking. ACM Transactions on Computer-Human Interaction 27, 4: 22:1-22:24. https://doi.org/10.1145/3397178.

[40] Sarah E. Fox, Rafael M.L. Silva, and Daniela K. Rosner. 2018. Beyond the Prototype: Maintenance, Collective Responsibility, and Public IoT. In Proceedings of the 2018 Designing Interactive Systems Conference (DIS '18), 21-32. https://doi.org/10.1145/3196709.3196710.

[41] Sarah Fox, Noura Howell, Richmond Wong, and Franchesca Spektor. 2019. Vivewell: Speculating Near-Future Menstrual Tracking Through Current Data Practices. In Proceedings of the 2019 on Designing Interactive Systems Conference (DIS '19), 541-552. https://doi.org/10.1145/3322276.3323695.

[42] Katie Gambier-Ross, David J McLernon, and Heather M Morgan. 2018. A mixed methods exploratory study of women's relationships with and uses of fertility tracking apps. DIGITAL HEALTH 4: 2055207618785077. https://doi.org/10.1177/ 2055207618785077.

[43] Arthur Greil, Julia McQuillan, and Kathleen Slauson-Blevins. 2011. The social construction of infertility. Sociology Compass 5, 8: 736-746.

[44] Xinning Gui, Yu Chen, Yubo Kou, Katie Pine, and Yunan Chen. 2017. Investigating Support Seeking from Peers for Pregnancy in Online Health Communities. Proc. ACM Hum.-Comput. Interact. 1, CSCW: 50:1-50:19. https: //doi.org/10.1145/3134685.

[45] Xinning Gui and Yunan Chen. 2019. Making Healthcare Infrastructure Work: Unpacking the Infrastructuring Work of Individuals. In Proceedings of the 2019 CHI Conference on Human Factors in Computing Systems (CHI '19), 458:1458:14. https://doi.org/10.1145/3290605.3300688.

[46] Xinning Gui, Yunan Chen, and Kathleen H. Pine. 2018. Navigating the Healthcare Service "Black Box": Individual Competence and Fragmented System. Proc. ACM Hum.-Comput. Interact. 2, CSCW: 61:1-61:26. https://doi.org/10.1145/3274330.

[47] Linda F. Hogle. 2016. Data-intensive resourcing in healthcare. BioSocieties 11, 3: 372-393. https://doi.org/10.1057/s41292-016-0004-5.

[48] Sarah Homewood, Harvey Bewley, and Laurens Boer. 2019. Ovum: Designing for Fertility Tracking as a Shared and Domestic Experience. 553-565.

[49] Sarah Homewood, Laurens Boer, and Anna Vallgårda. 2020. Designers in White Coats: Deploying Ovum, a Fertility Tracking Device. In Proceedings of the 2020 CHI Conference on Human Factors in Computing Systems, 1-13. 
[50] Sarah Homewood, Amanda Karlsson, and Anna Vallgårda. 2020. Removal as a Method: A Fourth Wave HCI Approach to Understanding the Experience of Self-Tracking. 1779-1791.

[51] Matthew K. Hong, Lauren Wilcox, Daniel Machado, Thomas A. Olson, and Stephen F. Simoneaux. 2016. Care Partnerships: Toward Technology to Support Teens' Participation in Their Health Care. Proceedings of the SIGCHI conference on human factors in computing systems . CHI Conference 2016: 5337-5349. https://doi.org/10.1145/2858036.2858508.

[52] Marcia C Inhorn, Rosario Ceballo, and Robert Nachtigall. 2009. Marginalized, in visible, and unwanted: American minority struggles with infertility and assisted conception. Marginalized reproduction: Ethnicity, infertility and reproductive technologies 11: 181-97.

[53] Maia L. Jacobs, James Clawson, and Elizabeth D. Mynatt. 2015. Comparing Health Information Sharing Preferences of Cancer Patients, Doctors, and Navigators. In Proceedings of the 18th ACM Conference on Computer Supported Cooperative Work \& Social Computing (CSCW '15), 808-818. https: //doi.org/10.1145/2675133.2675252.

[54] Minal Jain and Pradeep Yammiyavar. 2015. Game Based Learning Tool Seeking Peer Support for Empowering Adolescent Girls in Rural Assam. In Proceedings of the 14th International Conference on Interaction Design and Children (IDC '15), 275-278. https://doi.org/10.1145/2771839.2771895.

[55] Hee Young Jeong and Rosa I Arriaga. 2009. Using an ecological framework to design mobile technologies for pediatric asthma management. 1-4.

[56] Sandra Jovchelovitch and Martin W. Bauer. 2000. Narrative interviewing. Qualitative researching with text, image and sound: $57-74$

[57] Ntwa Katule, Melissa Densmore, and Ulrike Rivett. 2016. Leveraging Intermediated Interactions to Support Utilization of Persuasive Personal Health Informatics. In Proceedings of the Eighth International Conference on Information and Communication Technologies and Development (ICTD '16), 19:1-19:11. https://doi.org/10.1145/2909609.2909664.

[58] Dmitri Katz, Blaine Price, Simon Holland, and Nick Dalton. 2018. Data, Data Everywhere, and Still Too Hard to Link: Insights from User Interactions with Diabetes Apps. Retrieved April 2, 2018 from http://nrl.northumbria.ac.uk/33422/.

[59] Elizabeth Kaziunas, Mark S. Ackerman, Silvia Lindtner, and Joyce M. Lee. 2017 Caring through Data: Attending to the Social and Emotional Experiences of Health Datafication. 2260-2272. https://doi.org/10.1145/2998181.2998303.

[60] Elizabeth Kaziunas, Michael S. Klinkman, and Mark S. Ackerman. 2019. Precari ous Interventions: Designing for Ecologies of Care. Proceedings of the ACM on Human-Computer Interaction 3, CSCW: 113:1-113:27. https://doi.org/10.1145/ 3359215.

[61] Os Keyes, Burren Peil, Rua M. Williams, and Katta Spiel. 2020. Reimagining (Women's) Health: HCI, Gender and Essentialised Embodiment. ACM Transac tions on Computer-Human Interaction 27, 4: 25:1-25:42. https://doi.org/10.1145/ 3404218.

[62] Neha Kumar, Naveena Karusala, Azra Ismail, and Anupriya Tuli. 2020. Tak ing the Long, Holistic, and Intersectional View to Women's Wellbeing. ACM Transactions on Computer-Human Interaction (TOCHI) 27, 4: 1-32.

[63] Amanda Lazar, Norman Makoto Su, Jeffrey Bardzell, and Shaowen Bardzell. 2019. Parting the Red Sea: Sociotechnical Systems and Lived Experiences of Menopause. In Proceedings of the 2019 CHI Conference on Human Factors in Computing Systems (CHI '19), 480:1-480:16. https://doi.org/10.1145/3290605. 3300710.

[64] Mihan Lee. 2017. Don't Give Up! A Cyber-ethnography and Discourse Analysis of an Online Infertility Patient Forum. Culture, Medicine, and Psychiatry 41, 3 : 341-367. https://doi.org/10.1007/s11013-016-9515-6.

[65] Ian Li, Anind Dey, and Jodi Forlizzi. 2010. A Stage-based Model of Personal Informatics Systems. In Proceedings of the SIGCHI Conference on Human Fac tors in Computing Systems (CHI '10), 557-566. https://doi.org/10.1145/1753326. 1753409

[66] Leslie S. Liu, Sen H. Hirano, Monica Tentori, Karen G. Cheng, Sheba George, Sun Young Park, and Gillian R. Hayes. 2011. Improving Communication and Socia Support for Caregivers of High-risk Infants Through Mobile Technologies. In Proceedings of the ACM 2011 Conference on Computer Supported Cooperative Work (CSCW '11), 475-484. https://doi.org/10.1145/1958824.1958897.

[67] Yuhan Luo, Peiyi Liu, and Eun Kyoung Choe. 2019. Co-Designing Food Trackers with Dietitians: Identifying Design Opportunities for Food Tracker Customization. In Proceedings of the 2019 CHI Conference on Human Factors in Computing Systems (CHI '19), 1-13. https://doi.org/10.1145/3290605.3300822.

[68] Deborah Lupton. 2013a. The digitally engaged patient: Self-monitoring and self-care in the digital health era. Social Theory \& Health 11, 3: 256-270.

[69] Deborah Lupton. 2015. Quantified sex: a critical analysis of sexual and reproductive self-tracking using apps. Culture, Health \& Sexuality 17, 4: 440-453. https://doi.org/10.1080/13691058.2014.920528.

[70] Haley MacLeod, Kim Oakes, Danika Geisler, Kay Connelly, and Katie Siek. 2015 Rare World: Towards Technology for Rare Diseases. In Proceedings of the 33rd Annual ACM Conference on Human Factors in Computing Systems (CHI '15) 1145-1154. https://doi.org/10.1145/2702123.2702494.
[71] Maya N. Mascarenhas, Seth R. Flaxman, Ties Boerma, Sheryl Vanderpoel, and Gretchen A. Stevens. 2012. National, Regional, and Global Trends in Infertility Prevalence Since 1990: A Systematic Analysis of 277 Health Surveys. PLOS Medicine 9, 12: e1001356. https://doi.org/10.1371/journal.pmed.1001356.

[72] Tristan D. McBain and Patricia Reeves. 2019. Women's Experience of Infertility and Disenfranchised Grief: The Family Journal. https://doi.org/10.1177/ 1066480719833418.

[73] Mollie McKillop, Lena Mamykina, and Noémie Elhadad. 2018. Designing in the Dark: Eliciting Self-tracking Dimensions for Understanding Enigmatic Disease. In Proceedings of the $2018 \mathrm{CHI}$ Conference on Human Factors in Computing Systems (CHI '18), 565:1-565:15. https://doi.org/10.1145/3173574.3174139.

[74] Sonali R. Mishra, Predrag Klasnja, John MacDuffie Woodburn, Eric B. Hekler, Larsson Omberg, Michael Kellen, and Lara Mangravite. 2019. Supporting Coping with Parkinson's Disease Through Self Tracking. In Proceedings of the 2019 CHI Conference on Human Factors in Computing Systems (CHI '19), 1-16. https://doi.org/10.1145/3290605.3300337.

[75] Elizabeth L. Murnane, Tara G. Walker, Beck Tench, Stephen Voida, and Jaime Snyder. 2018. Personal Informatics in Interpersonal Contexts: Towards the Design of Technology That Supports the Social Ecologies of Long-Term Mental Health Management. Proc. ACM Hum.-Comput. Interact. 2, CSCW: 127:1-127:27. https://doi.org/10.1145/3274396.

[76] Sarah Ng, Shaowen Bardzell, and Jeffrey Bardzell. 2020. The Menstruating Entrepreneur Kickstarting a New Politics of Women's Health. ACM Transactions on Computer-Human Interaction 27, 4: 21:1-21:25. https://doi.org/10.1145/ 3397158.

[77] Francisco Nunes and Geraldine Fitzpatrick. 2015. Self-Care Technologies and Collaboration. International Journal of Human-Computer Interaction 31, 12: 869-881. https://doi.org/10.1080/10447318.2015.1067498.

[78] Andrea Parker, Vasudhara Kantroo, Hee Rin Lee, Miguel Osornio, Mansi Sharma, and Rebecca Grinter. 2012. Health promotion as activism: building community capacity to effect social change. In Proceedings of the SIGCHI Conference on Human Factors in Computing Systems (CHI '12), 99-108. https://doi.org/10. 1145/2207676.2207692.

[79] Dilisha Patel, Ann Blandford, Mark Warner, Jill Shawe, and Judith Stephenson. 2019. "I feel like only half a man" Online Forums as a Resource for Finding a" New Normal" for Men Experiencing Fertility Issues. Proceedings of the ACM on Human-Computer Interaction 3, CSCW: 1-20.

[80] Tamara Peyton, Erika Poole, Madhu Reddy, Jennifer Kraschnewski, and Cynthia Chuang. 2014. "Every Pregnancy is Different": Designing mHealth for the Pregnancy Ecology. In Proceedings of the 2014 Conference on Designing Interactive Systems (DIS '14), 577-586. https://doi.org/10.1145/2598510.2598572.

[81] Laura R. Pina, Sang-Wha Sien, Teresa Ward, Jason C. Yip, Sean A. Munson, James Fogarty, and Julie A. Kientz. 2017. From Personal Informatics to Family Informatics: Understanding Family Practices Around Health Monitoring. In Proceedings of the 2017 ACM Conference on Computer Supported Cooperative Work and Social Computing (CSCW '17), 2300-2315. https://doi.org/10.1145/ 2998181.2998362.

[82] Alexander Quaas and Anuja Dokras. 2008. Diagnosis and treatment of unexplained infertility. Reviews in obstetrics and gynecology 1, 2: 69 .

[83] Shriti Raj, Mark W. Newman, Joyce M. Lee, and Mark S. Ackerman. 2017. Understanding Individual and Collaborative Problem-Solving with Patient-Generated Data: Challenges and Opportunities. Proc. ACM Hum.-Comput. Interact. 1, CSCW: 88:1-88:18. https://doi.org/10.1145/3134723.

[84] Gerhard Riemann and Fritz Schütze. 1991. Trajectory as a basic theoretical concept for analyzing suffering and disorderly social processes. Social organization and social process. Essays in honor of Anselm Strauss: 333-357.

[85] John Rooksby, Mattias Rost, Alistair Morrison, and Matthew Chalmers Chalmers. 2014. Personal Tracking As Lived Informatics. In Proceedings of the $32 \mathrm{Nd}$ Annual ACM Conference on Human Factors in Computing Systems (CHI '14), 1163-1172. https://doi.org/10.1145/2556288.2557039.

[86] Minna Ruckenstein and Natasha Dow Schüll. 2017. The Datafication of Health. Annual Review of Anthropology 46, 1: 261-278. https://doi.org/10.1146/annurevanthro-102116-041244.

[87] Herman Saksono, Carmen Castaneda-Sceppa, Jessica Hoffman, Magy Seif ElNasr, Vivien Morris, and Andrea G Parker. 2018. Family health promotion in low-SES neighborhoods: A two-month study of wearable activity tracking. 1-13.

[88] Herman Saksono, Carmen Castaneda-Sceppa, Jessica Hoffman, Magy Seif ElNasr, Vivien Morris, and Andrea G Parker. 2019. Social reflections on fitness tracking data: A study with families in low-SES neighborhoods. 1-14.

[89] Johnny Saldaña. 2015. The coding manual for qualitative researchers. Sage.

[90] Patrick Sanger, Andrea Hartzler, Ross J. Lordon, Cheryl Al Armstrong, William B. Lober, Heather L. Evans, and Wanda Pratt. 2016. A patient-centered system in a provider-centered world: challenges of incorporating post-discharge wound data into practice. Journal of the American Medical Informatics Association: JAMIA 23, 3: 514-525. https://doi.org/10.1093/jamia/ocv183.

[91] Jessica Schroeder, Jane Hoffswell, Chia-Fang Chung, James Fogarty, Sean Munson, and Jasmine Zia. 2017. Supporting Patient-Provider Collaboration 
to Identify Individual Triggers using Food and Symptom Journals. CSCW: proceedings of the Conference on Computer-Supported Cooperative Work. Con ference on Computer-Supported Cooperative Work 2017: 1726-1739. https: //doi.org/10.1145/2998181.2998276.

[92] Leon Speroff and Marc A. Fritz. 2005. Clinical Gynecologic Endocrinology and Infertility. Lippincott Williams \& Wilkins.

[93] Katta Spiel, Fares Kayali, Louise Horvath, Michael Penkler, Sabine Harrer Miguel Sicart, and Jessica Hammer. 2018. Fitter, Happier, More Productive? The Normative Ontology of Fitness Trackers. In Extended Abstracts of the 2018 CHI Conference on Human Factors in Computing Systems (CHI EA '18), 1-10. https://doi.org/10.1145/3170427.3188401.

[94] Susan Leigh Star and Anselm Strauss. 1999. Layers of silence, arenas of voice: The ecology of visible and invisible work. Computer supported cooperative work (CSCW) 8, 1-2: 9-30.

[95] Anselm Strauss, Shizuko Fagerhaugh, Barbara Suczek, and Carolyn Wiener. 1985. Social organization of medical work. University of Chicago Press, Chicago, IL, US.

[96] Richard L. Street Jr, Lin Liu, Neil J. Farber, Yunan Chen, Alan Calvitti, Danielle Zuest, Mark T. Gabuzda, Kristin Bell, Barbara Gray, and Steven Rick. 2014 Provider interaction with the electronic health record: the effects on patientcentered communication in medical encounters. Patient education and counseling 96, 3: 315-319.

[97] Lucy Suchman. 1995. Supporting articulation work. In Computerization and controversy (2nd ed.): value conflicts and social choices. Academic Press, Inc., USA, $407-423$
[98] Anupriya Tuli, Shaan Chopra, Neha Kumar, and Pushpendra Singh. 2018. Learning from and with Menstrupedia: Towards Menstrual Health Education in India. Proc. ACM Hum.-Comput. Interact. 2, CSCW: 174:1-174:20. https://doi.org/10.1145/3274443

[99] Anupriya Tuli, Shruti Dalvi, Neha Kumar, and Pushpendra Singh. 2019. "It's a Girl Thing": Examining Challenges and Opportunities Around Menstrual Health Education in India. ACM Trans. Comput.-Hum. Interact. 26, 5: 29:1-29:24. https://doi.org/10.1145/3325282.

[100] Tiffany C Veinot, Hannah Mitchell, and Jessica S Ancker. 2018. Good intentions are not enough: how informatics interventions can worsen inequality. Journal of the American Medical Informatics Association 25, 8: 1080-1088.

[101] Carolyn L. Wiener and Marilyn J. Dodd. 1993. Coping amid uncertainty: An illness trajectory perspective. Scholarly inquiry for nursing practice 7: 17-17.

[102] World Health Organization. WHO | Infertility is a global public health issue. WHO. Retrieved September 10, 2020 from http://www.who.int/ reproductivehealth/topics/infertility/perspective/en/.

[103] Alyson L. Young and Andrew D. Miller. 2019. "This Girl is on Fire": Sensemaking in an Online Health Community for Vulvodynia. In Proceedings of the $2019 \mathrm{CH}$ Conference on Human Factors in Computing Systems (CHI '19), 129:1-129:13. https://doi.org/10.1145/3290605.3300359.

[104] Computational Support for Substance Use Disorder Prevention, Detection, Treatment, and Recovery - CCC. Retrieved September 8, 2020 from https: //cra.org/ccc/events/mental-health-and-addiction/.

[105] Data 4 Black Lives. Retrieved September 15, 2020 from https://d4bl.org/. 